\title{
DÜBLIN
}

Technological University Dublin

ARROW@TU Dublin

\section{Zein film: Effects of Dielectric Barrier Discharge Atmospheric Cold Plasma}

\author{
Shashi Pankaj \\ Technological University Dublin, shashi.pankaj@tudublin.ie \\ Carmen Bueno-Ferrer \\ Technological University Dublin \\ N. Misra \\ Technological University Dublin, misra.nrusimhanath@tudublin.ie
}

See next page for additional authors

Follow this and additional works at: https://arrow.tudublin.ie/schfsehart

Part of the Food Science Commons, and the Materials Science and Engineering Commons

\section{Recommended Citation}

Pankaj, S. K., Bueno-Ferrer, C., Misra, N. N., Bourke, P., \& Cullen, P. J. (2014). Zein film: Effects of dielectric barrier discharge atmospheric cold plasma. Journal of Applied Polymer Science. April

2014.http://dx.doi.org/10.1002/app.40803

This Article is brought to you for free and open access by the School of Food Science and Environmental Health at ARROW@TU Dublin. It has been accepted for inclusion in Articles by an authorized administrator of ARROW@TU Dublin. For more information, please contact arrow.admin@tudublin.ie, aisling.coyne@tudublin.ie, gerard.connolly@tudublin.ie.

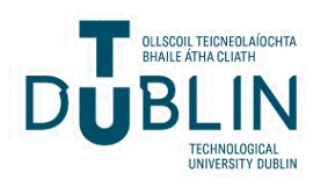




\section{Authors}

Shashi Pankaj, Carmen Bueno-Ferrer, N. Misra, Paula Bourke, and Patrick Cullen

This article is available at ARROW@TU Dublin: https://arrow.tudublin.ie/schfsehart/146 


\title{
Zein film: Effects of dielectric barrier discharge atmospheric cold plasma
}

S.K. Pankaj ${ }^{1}$, Carmen Bueno-Ferrer ${ }^{1}$, N.N. Misra ${ }^{1}$, Paula Bourke ${ }^{1}$, P.J. Cullen ${ }^{1,2}$

${ }^{1}$ BioPlasma Research group, School of Food Science and Environmental Health, Dublin Institute of Technology, Cathal Brugha Street, Dublin 1, Ireland

${ }^{2}$ School of Chemical Engineering, UNSW Australia, Sydney NSW 2052 Australia

Correspondence to: Patrick Cullen (pjcullen@dit.ie)

\begin{abstract}
Dielectric barrier discharge atmospheric plasma is a novel non-thermal technology for the food and packaging industry. The effects of dielectric barrier discharge plasma on the surface, structural, thermal and moisture sorption properties of edible zein films have been examined. Plasma treatment increased the surface roughness and equillibrium moisture content of the zein film in a direct relationship with the applied voltage level. No significant difference in the thermal stability of the zein film is also observed after plasma treatment. Dielectric barrier discharge plasma treatments of zein film lead to a change in the protein conformation which is confirmed by X-ray diffraction and Fourier transform Infrared spectroscopy. The evaluation of films modifications by plasma discharge will contribute to enhance the in-package decontamination studies of food products by plasma.
\end{abstract}

KEYWORDS: Zein, ACP, DBD, plasma, AFM, XRD, FTIR 


\section{INTRODUCTION}

Biodegradable polymers from renewable resources have shown significant potential in packaging applications due to their environmental benefits. Whilst biodegradable packaging materials have limitations pertaining to properties and cost, the fact that certain chemicals used for synthetic packaging are endocrine disrupters and lead to greenhouse gases, the demand for eco-friendly wrappings has increased. ${ }^{1,2}$ Zein, is a primary byproduct of the bioethanol industry thus justifying its practicality for efficient utilization of green biomass.

Zein was first described by John Gorham in 1821 after isolating the protein from corn and in 1909 , the first patent was granted for preparing plastic from zein. ${ }^{3,4}$ Zein is a water-insoluble prolamin present in corn endosperm cells with a high content of hydrophobic amino acids (leucine, proline and alanine). ${ }^{5}$ Zein can be cast into films by dissolving it in a hydrated organic solvent, such as ethanol or acetone, and then drying. ${ }^{6}$ However, films made of $100 \%$ zein are brittle, therefore plasticizers are added to improve flexibility. ${ }^{7}$ Zein films are distinctive as they are tough, glossy, hydrophobic, greaseproof, and resistant to microbial attack ensuring its suitability as coatings, fibers and packaging films for food and pharmaceutical industries. ${ }^{5,8}$ The effectiveness of using zein films as edible coating for maintaining post-harvest quality has been demonstrated for produce including; apple, broccoli and tomato. ${ }^{9-11}$

Recently, Atmospheric Cold Plasma (ACP) has gained attention for the decontamination of fresh fruits and vegetables. ${ }^{12-14}$ ACP is characterized by the disequilibrium of temperature between electrons and ions and can be generated by various methods. ${ }^{15}$ Dielectric barrier discharge (DBD) is one of the common methods to generate ACP. In most common DBD devices, plasma is 
generated between two plane-parallel metal electrodes among which at least one of the electrodes is covered by a dielectric layer. A filamentary discharge is formed by microdischarges or streamers, which develop on the dielectric layer surface. The dielectric layer plays an important role in limiting the discharge current to avoid an arc transition and to randomly distribute streamers on the electrode surface resulting a homogeneous treatment. ${ }^{16} \mathrm{DBD}$ plasma is well known for the modification of both the surface and bulk properties of polymers.

${ }^{17}$ The effects of DBD plasma on conventional polymers like polyethylene, polypropylene, poly(ethylene terephthalate) and polystyrene have been reported but there is limited information available on the effects of DBD plasma on biodegradable polymers. ${ }^{18-22}$ The aim of this work is to characterize the effects of DBD ACP plasma treatments on surface, structural, thermal and moisture sorption properties of biodegradable corn zein films.

\section{EXPERIMENTAL}

\section{Materials}

Zein films were prepared as described by Mastromatteo, Barbuzzi, Conte and Del Nobile ${ }^{23}$ with slight modifications. 5g of zein (Sigma-Aldrich, Ireland) were dissolved into $26 \mathrm{~mL}$ of 95\% ethanol at $50^{\circ} \mathrm{C} .3 \mathrm{~g}$ of glycerol (Sigma-Aldrich, Ireland) were added to the solution and stirred using a hotplate magnetic stirrer for $10 \mathrm{~min}$. The film forming solutions were poured on Petri dishes (diameter $15 \mathrm{~cm}$ ) and dried at ambient conditions under laminar flow hood until the solvent was completely evaporated and peeled off after 48 hours. The cast zein films had an average thickness of $385 \pm 10 \mu \mathrm{m}$. 


\section{Plasma treatment}

A schematic of the experimental setup is presented in Figure 1. The DBD plasma source consists of two circular aluminium plate electrodes (outer diameter $=158 \mathrm{~mm}$ ) over perspex dielectric layers (10 $\mathrm{mm}$ thickness). The applied voltage to the electrode was obtained from a step-up transformer (Phenix Technologies, Inc., USA). The input voltage to the primary winding was $230 \mathrm{~V}$ at a frequency of $50 \mathrm{~Hz}$. A 2-mm-thick polypropylene sheet was used to stabilize the discharge. The distance between electrodes was $22 \mathrm{~mm}$. The atmospheric air conditions at the time of treatment were $48 \%$ relative humidity $(\mathrm{RH})$ and $20^{\circ} \mathrm{C}$. The samples were treated at 60 , 70 and $80 \mathrm{kV}$ for 1, 2, 3, 4 and 5 minutes.

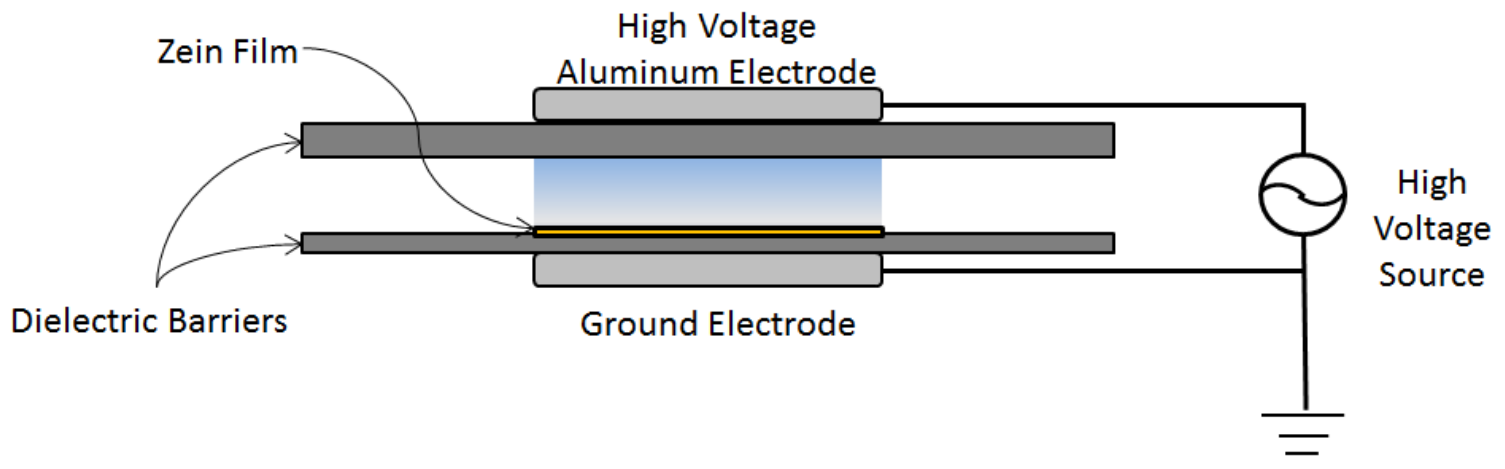

FIGURE 1: Schematic of the experimental setup for DBD plasma system.

\section{Material characterization}

\section{Atomic force microscopy (AFM)}

AFM measurements were carried out to observe the surface topography of the samples before and after DBD plasma treatment. The AFM used was MFP-3D BIO 1126 (Asylum Research, Santa 
Barbara, CA, USA) operated in intermittent contact (tapping) mode. The images were collected at a fixed scan rate of $0.5 \mathrm{~Hz}$. The sampling rate was 512 lines. The data was processed using MF3D software (version $111111+1219)$.

\section{Water Sorption Kinetics}

Water sorption kinetics was determined by the method of Pereda, Aranguren and Marcovich ${ }^{24}$. Briefly, the films were dried at $40^{\circ} \mathrm{C}$ for three days in a vacuum oven at $500 \mathrm{~mm}$ pressure at $25^{\circ} \mathrm{C}$. After drying, films were DBD plasma treated and placed in a versatile environmental test chamber (Model MLR-350H, Sanyo Electric Biomedical Co. Itd., Japan) at a controlled humidity environment of $75 \%$ at $23^{\circ} \mathrm{C}$. Samples were weighed gravimetrically at equal time intervals with a precision of $\pm 0.0001 \mathrm{~g}$. This experiment was performed in triplicate to ensure the reproducibility of the results. The moisture content $\left(\mathrm{M}_{\mathrm{t}}\right)$ of films as a function of time was obtained from the total mass balance of the sample as a function of time as given in equation 1.

$$
M_{t}(\%)=\frac{\left(W_{t}-W_{0}\right) \times 100}{W_{0}}
$$

where $M_{t}=$ moisture content of the sample at time $t(\%), W_{t}=$ weight of the sample at time $t(g)$, $\mathrm{W}_{0}=$ initial dry weight of sample $(\mathrm{g})$.

\section{Thermogravimetric analysis (TGA)}

TGA analysis was performed with a DTG-60 instrument (Shimadzu, Ireland). Samples were heated at $10^{\circ} \mathrm{C} \mathrm{min}^{-1}$ from room temperature to $700^{\circ} \mathrm{C}$ under nitrogen atmosphere (flow rate 
$\left.50 \mathrm{ml} \mathrm{min}{ }^{-1}\right)$. The initial degradation temperature $\left(T_{5}\right)$ was determined as the temperature at which $5 \%$ of mass was lost.

\section{Differential scanning calorimetry (DSC)}

DSC analysis was performed with a Differential Scanning Calorimeter DSC2010 with a refrigerating cooling system (RCS) (TA Instruments, AGB Scientific, Dublin, Ireland) under a dry

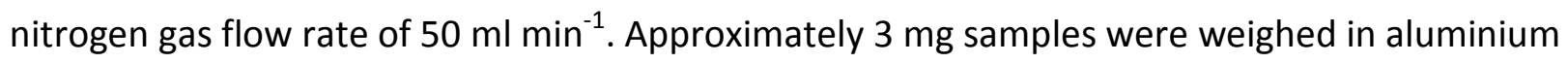
pans $(40 \mu \mathrm{L})$ and subjected to heating-cooling cycles from $-30^{\circ} \mathrm{C}$ to $200^{\circ} \mathrm{C}$ at $10^{\circ} \mathrm{C} \mathrm{min}{ }^{-1}$. Glass transition temperatures $\left(T_{\mathrm{g}}\right)$ and melting endotherm were determined in the first heating scan.

\section{X-ray diffraction (XRD)}

Wide-angle X-ray scattering (WAXS) was performed on a Bruker D8-Advance (USA) diffractometer, equipped with a Cu-K $\alpha$ radiation source $(\lambda=1.546 \AA)$, operating at $40 \mathrm{kV}$ and 40 $\mathrm{mA}$ as the applied voltage and current, respectively. The incidence angle (20) was varied between $5^{\circ}$ and $90^{\circ}$ at a scanning rate of $2^{\circ} \mathrm{min}^{-1}$.

\section{Fourier transform infrared spectroscopy (FTIR)}

FTIR spectroscopy was carried out by using a Perkin Elmer FT-IR/FT-NIR spectrometer(Spectrum 400) from 4000 to $400 \mathrm{~cm}^{-1}$ to measure any changes in the spectra intensities. A background spectrum was collected by keeping the resolution as $4 \mathrm{~cm}^{-1}$. After the background scan, treated and untreated film samples were placed in the sample holder and analyzed. 


\section{RESULTS AND DISCUSSIONS}

\section{Surface Properties}

DBD plasma is known for increasing the surface roughness of polymers due to the etching effect. Etching by DBD plasma can be due to chemical (breaking of bonds, chain scission, chemical degradation) or physical processes (physically removal of low molecular fragments). ${ }^{25-}$

27 The possibility of a change in surface roughness resulting from micro-discharge filaments cannot be also completely overruled. The AFM topography of the zein surface is shown in Figure 2 and the roughness parameters are shown in Table 1. It is evident that DBD plasma treatment increased the surface roughness of the zein film. Surface roughness was observed to be increasing with an increase in the applied voltage and treatment time. Similar increases in the surface roughness after plasma treatment have also been reported for common polymers such as; low-density polyethylene, polypropylene, poly(ethylene terephthalate) and poly(lactic acid). ${ }^{19,28-30}$ 

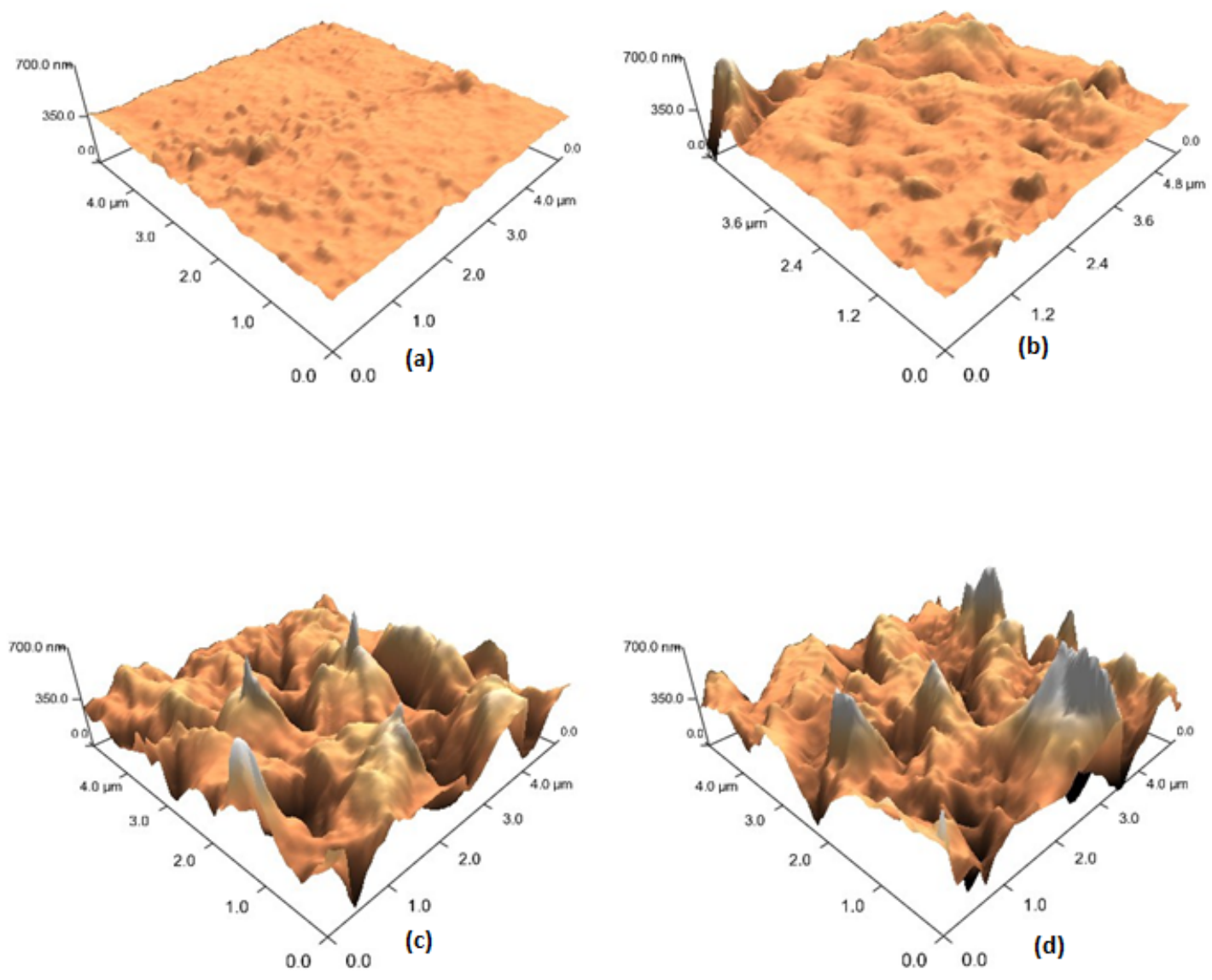

FIGURE 2: AFM images of the surface of untreated and plasma-treated cast zein films

(a) Untreated, (b) 60 kV-5min, (c) 70 kV-5, (d) 80 kV-5. 
TABLE 1: Roughness parameters for control and DBD plasma treated cast zein films ( $\mathrm{R}_{\mathrm{RMs}}$ : root

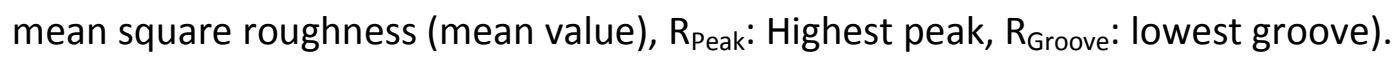

\begin{tabular}{ccccc}
\hline Voltage (kV) & Time $(\min )$ & $\mathbf{R}_{\mathrm{RMS}}(\mathbf{n m})$ & $\mathbf{R}_{\text {Peak }}(\mathbf{n m})$ & $\mathbf{R}_{\text {Groove }}(\mathbf{n m})$ \\
\hline \multirow{2}{*}{ Control } & & 16.410 & 125.991 & 66.995 \\
\hline 60 & 5 & 52.044 & 295.146 & 337.616 \\
\hline 70 & 5 & 126.164 & 496.313 & 506.472 \\
\hline 80 & 5 & 132.869 & 641.017 & 651.892 \\
\hline
\end{tabular}

\section{Water Sorption Kinetics}

Generally, protein films have poor moisture barrier properties due to their hydrophilic nature.

Use of glycerol as plasticizer further increases the moisture sorption capacity due to its hydrophilic nature as shown by Lawton ${ }^{31}$ and Wei and Baianu ${ }^{32}$. Water diffusion into hydrophilic polymers is associated with relaxation of the polymer chain and an increase in the free volume. There are many empirical and fundamental models proposed in the literature for the absorption of water in hydrophilic films. In this study the Peleg equation was chosen for the empirical description of the sorption process. This equation relates the moisture content at a given time $\left(M_{t}\right)$ with the initial moisture content $\left(M_{0}\right)$ as given in equation 2 .

$$
M_{t}=M_{0}+\frac{t}{K_{1}+K_{2} \cdot t}
$$


where $t$ is time $(\mathrm{min})$ and $K_{1}$ and $K_{2}$ are fitting parameters. $K_{1}$ is Peleg's rate factor (min/\%wt.) and is associated with the initial absorption rate, $\mathrm{K}_{2}$ is Peleg's capacity parameter $\left(\% \mathrm{wt}^{-1}\right)$ and is related to the final absorption capacity.

As a fundamental model describing the water absorption on films, Fick's second law intended for a plane sheet with constant boundary conditions and uniform initial concentration was used as reported in equation 3 .

$$
M(t)=M_{e q}\left[1-\frac{8}{\pi^{2}} \sum_{n=0}^{\infty} \frac{1}{(2 n+1)^{2}} \cdot \exp \left\{\frac{-D \cdot(2 n+1)^{2} \cdot \pi^{2} \cdot t}{h^{2}}\right\}\right]
$$

where $M(t)$ is the moisture content (\%) at time $t(s), M_{\text {eq }}$ is the moisture at equilibrium conditions (\%), D is the diffusion coefficient $\left(\mathrm{cm}^{2} \mathrm{~s}^{-1}\right)$ through the swollen polymeric matrix and $h$ is the film thickness $(\mathrm{cm})$.

Experimental moisture sorption data were fitted with the Peleg equation and Fick's diffusion model and the fitting parameters are reported in Table 2 (Figure 3). An increase in the equillibrium moisture content was observed after the DBD plasma treatment. This increase was found to be directly correlated with the treatment voltage. For the control film the equillibrium moisture content was $10.2 \%$ while after plasma treatment at $80 \mathrm{kV}$ for 5 minutes, it increased to 18.7\%. In the present study the Peleg equation was found to describe the process better than the Fickian model as evident from the root mean square error (RMSE) values. This can be explained by the fact that, Fick's model describes mass transport related to Brownian motions in which the penetrant flow is exclusively driven by a concentration gradient while water sorption in moderately hydrophilic polymers is a complex phenomenon due to the presence 
of specific interactions between water molecules and the hydrophilic sites on the polymer backbone. ${ }^{24}$ The system of DBD plasma discharge employed is a potential source of reactive oxygen (ROS) and reactive nitrogen species (RNS) which has been reported in previous studies. ${ }^{25}$ An increase in the surface oxygenation after plasma treatment has been observed by many authors leading to an increase in the hydrophillicity of the sample. ${ }^{17}$ This increase in the hydrophillicity can be correlated with the increased equillibrium moisture content of the films.

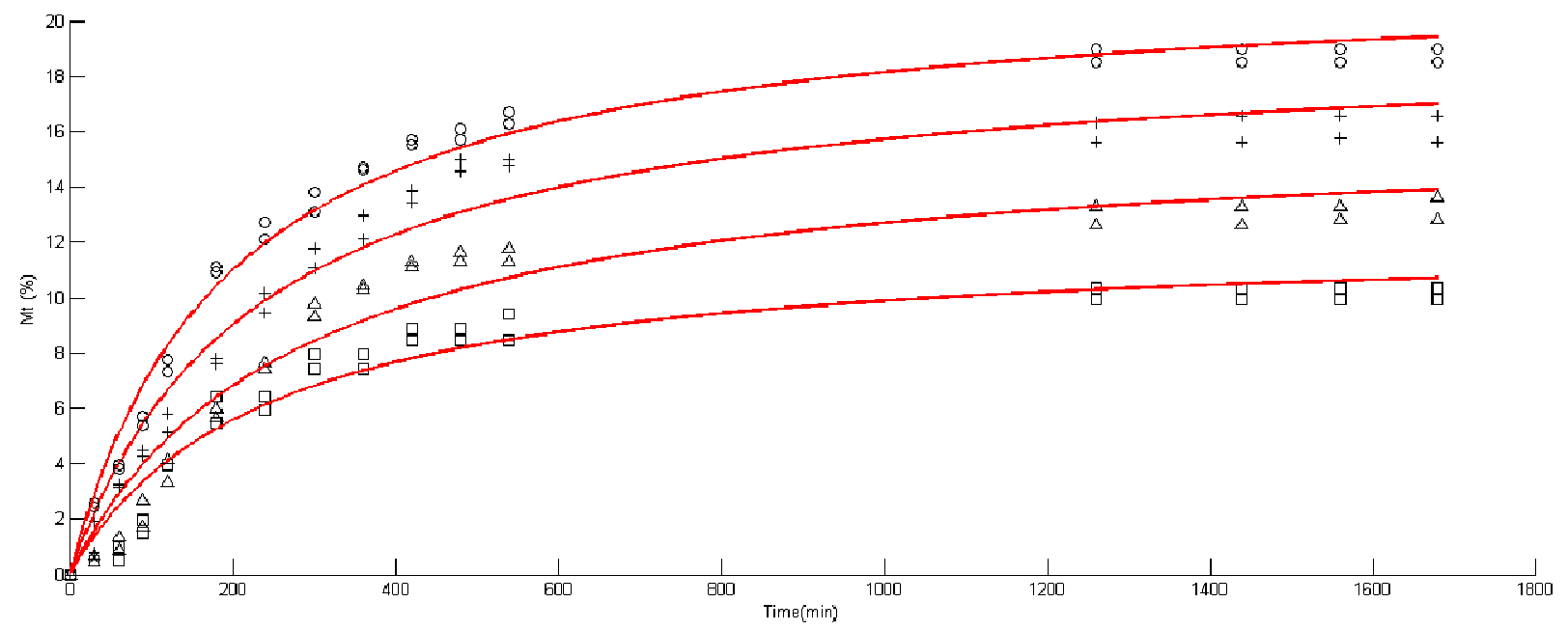

FIGURE 3: Moisture sorption of zein films after DBD plasma treatment at $23^{\circ} \mathrm{C}$ and $75 \% \mathrm{RH}$ (solid lines represent the fitting from the Peleg equation, Control( $\square$ ), 60kV-5min $(\Delta)$, 70kV$5 \min (+), 80 \mathrm{kV}-5 \min (0)$ 
TABLE 2: Fitting Parameters of the Peleg Equation and Fickian model for DBD plasma treated zein films.

\begin{tabular}{|c|c|c|c|c|c|c|}
\hline Treatments & \multicolumn{3}{|c|}{ Peleg Equation } & \multicolumn{3}{c|}{ Fickian Model } \\
\hline & $\mathrm{K}_{1}$ (min/\%wt.) & $\mathrm{K}_{2}\left(\% \mathrm{wt}^{-1}\right)$ & RMSE & $\mathrm{M}_{\mathrm{eq}}(\%)$ & $\mathrm{D}\left(\mathrm{cm}^{2} / \mathrm{s}\right)$ & RMSE \\
\hline Control & 19.51 & 0.082 & 0.84 & 10.43 & $6.85 \times 10^{-9}$ & 1.246 \\
\hline $60 \mathrm{kV} / 5 \mathrm{~min}$ & 17.06 & 0.062 & 1.11 & 13.95 & $5.81 \times 10^{-9}$ & 1.709 \\
\hline $70 \mathrm{kV} / 5 \mathrm{~min}$ & 11.86 & 0.052 & 0.99 & 16.93 & $6.63 \times 10^{-9}$ & 1.602 \\
\hline $80 \mathrm{kV} / 5 \mathrm{~min}$ & 8.994 & 0.046 & 0.72 & 19.18 & $7.64 \times 10^{-9}$ & 1.472 \\
\hline
\end{tabular}

\section{Thermal Properties}

The initial degradation temperature of zein film was not significantly $(p>0.05)$ different after DBD plasma treatment. The $T_{5}$ for untreated control zein film was $148.1^{\circ} \mathrm{C}$ while after plasma treatment it was in the range of $146.3^{\circ} \mathrm{C}$ to $150.6^{\circ} \mathrm{C}$. The initial step of mass loss for control film was found in the region of $78^{\circ} \mathrm{C}$ while after plasma treatment it was in the region of 82 to $93^{\circ} \mathrm{C}$ which also suggests the increase in water retention capacity of the zein film after plasma treatment. The results were different than the studies conducted on commercial biodegradable polymer like poly (lactic acid) where an increased thermal stability was observed. ${ }^{30}$

In the DSC thermogram, no significant change was observed in $\mathrm{T}_{\mathrm{g}}$ after plasma treatment and the values are in good agreement with other studies using glycerol as plasticizer. ${ }^{31,33}$ This implies that glycerol was effectively incorporated, by penetrating the protein network, forming hydrogen bonds with the protein molecules and thus increasing the separation between the 
protein chains. However, ACP treatment clearly changed the pattern of thermograms of the plasticized zein films, since an endothermic event between 50 and $55^{\circ} \mathrm{C}$ appears in all the treated samples, but it is not distinguishable in the control sample. This phenomenon was evident in the samples subjected to 5 min of treatment time (Figure 4). It is also noted that as voltage increases, enthalpies associated with this event are higher and peak shapes also differ, with three small peaks for samples treated at $60 \mathrm{kV}$ and one well-defined peak for sample treated at $80 \mathrm{kV}$ observed. Given the fact that this event appears just before the glass transition in all the samples, it could be attributed to a breakdown of cross-linkages leading to a reorganization of the protein conformational structure as the molecules obtain sufficient freedom of motion. 


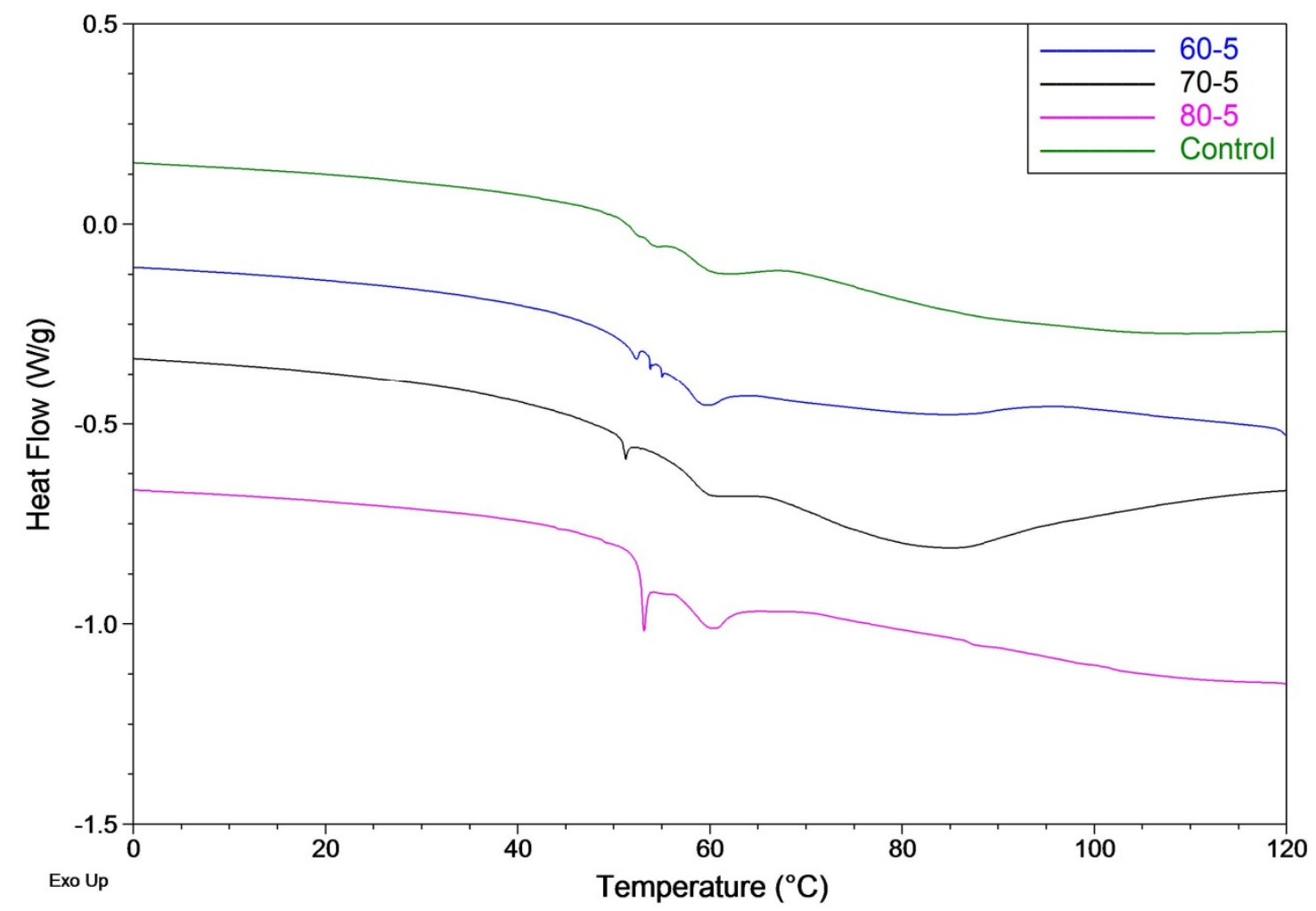

FIGURE 4: DSC thermogram of DBD plasma treated zein films. A-B: Voltage (kV)-Treatment time (min).

\section{X-ray diffraction (XRD)}

The WAXS pattern of zein films is shown in Figure 5. Two broad peaks appear in all the diffractograms at $2 \theta=8.7$ and $2 \theta=19.3$. By applying Bragg's law, distances of $10.1 \AA$ and $4.6 \AA$ respectively were calculated. The smaller distance (4.6 $\mathrm{A})$ corresponds to the average backbone distance within the $\alpha$-helix. The larger distance $(10.1 \AA)$ is related to the lateral $\alpha$-helix packing or the mean distance among neighboring helices. ${ }^{33-35}$ As evident from Figure $6 a$ and $6 \mathrm{~b}$, after ACP treatment of zein films at $60 \mathrm{kV}$ and $70 \mathrm{kV}$ there is a decrease in the intensity of the first 
peak. Since the $10.1 \AA$ is related to the inter-helix packing, the decline of intensity implies the disruption of zein molecular aggregates, which was also observed by Wang, Geil and Padua ${ }^{34}$ with the application of higher mechanical energy during film processing. At $80 \mathrm{kV}$, the reduction of the first peak's intensity was only observed after 1 minute of treatment. The second spacing corresponding to $4.6 \AA$ (peak at $2 \theta=19.3$ in Figure 6 ) was clearly less affected in all the plasma treated samples, suggesting that the helical configuration of zein was not disturbed by plasma treatment. 

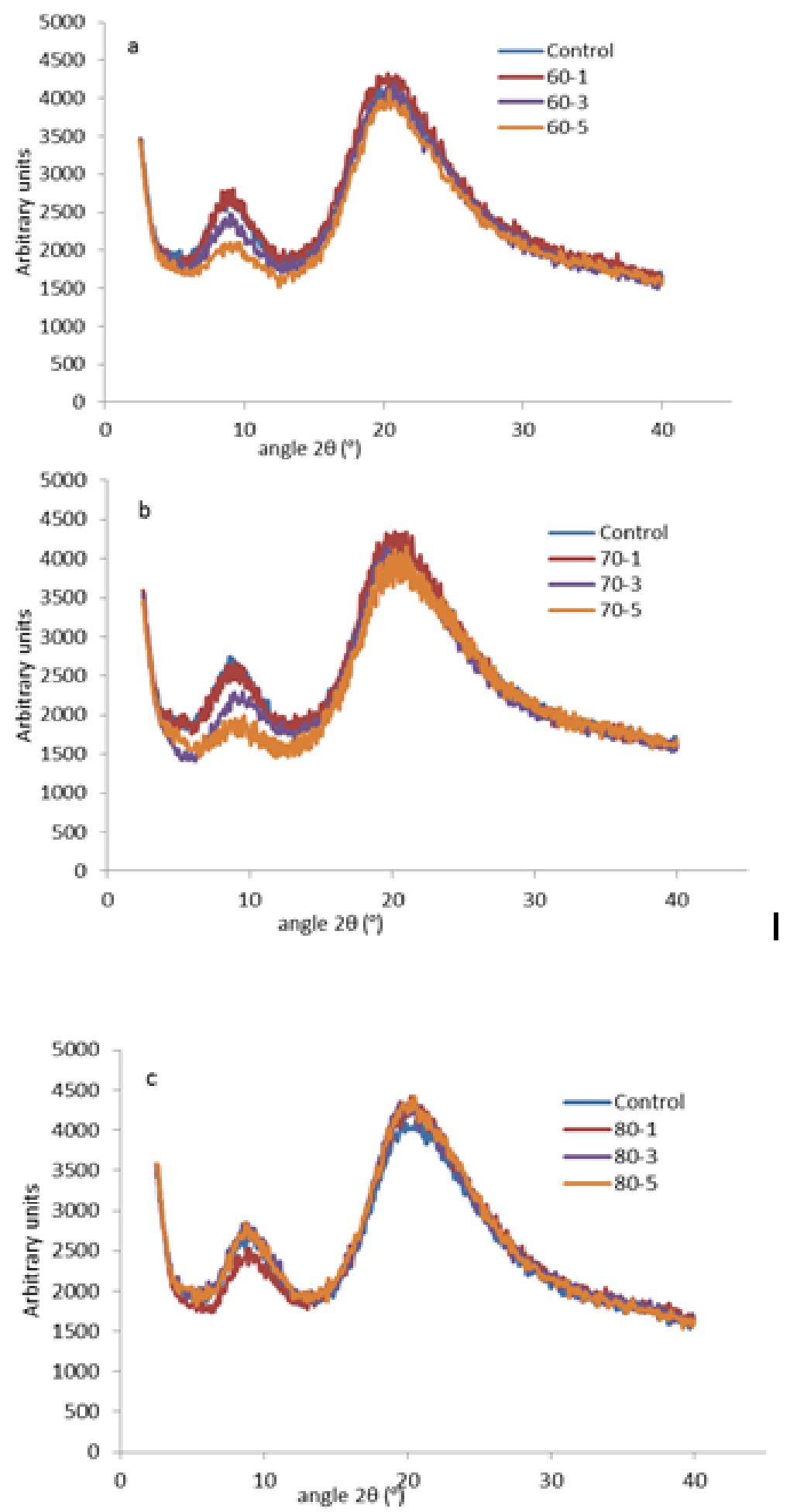

FIGURE 5: X-ray diffractogram of zein film after DBD plasma treatment at (a) 60kV (b) $70 \mathrm{kV}$ and (c) $80 \mathrm{kV}$. 


\section{Fourier transform infrared spectroscopy (FTIR)}

In the amide I region, band around $1650 \mathrm{~cm}^{-1}$ can be assigned to $\alpha$-helical and disordered conformation (stretching vibrations of the $\mathrm{C}=\mathrm{O}$ bond of the amide) and the band at $1685 \mathrm{~cm}^{-1}$ is due to $\beta$-sheets. ${ }^{36}$ A broad peak was observed around $1650 \mathrm{~cm}^{-1}$, which is consistent with an $\alpha$ helical structure (Figure 6). The increase of intensity observed at this band after DBD plasma treatment suggests that the ACP treatment increased the amount of $\alpha$-helical and disordered conformations. The result is in agreement with the DSC thermograms and XRD diffractogram which also suggested a change in the protein conformation after plasma treatment. An increase in the intensity of amide II band at $1540 \mathrm{~cm}^{-1}$ (bending vibrations of the $\mathrm{N}-\mathrm{H}$ bond) after DBD plasma treatment was also observed. This change may be due to two main factors (i) more extensive hydrogen bonding between the protein, reducing the number of non-bonded peptide groups and (ii) a shift from $\beta$-sheet structure, which absorbs around $1525 \mathrm{~cm}^{-1}$, to $\alpha$-helical structure, which has its amide II maximum at $1545 \mathrm{~cm}^{-1} .{ }^{37}$ Bands were also observed at the $2800-3000 \mathrm{~cm}^{-1}$ range, $1447 \mathrm{~cm}^{-1}$ and $720 \mathrm{~cm}^{-1}$ which are attributed to the vibrations of attached hydrocarbon chains. $^{38}$ 


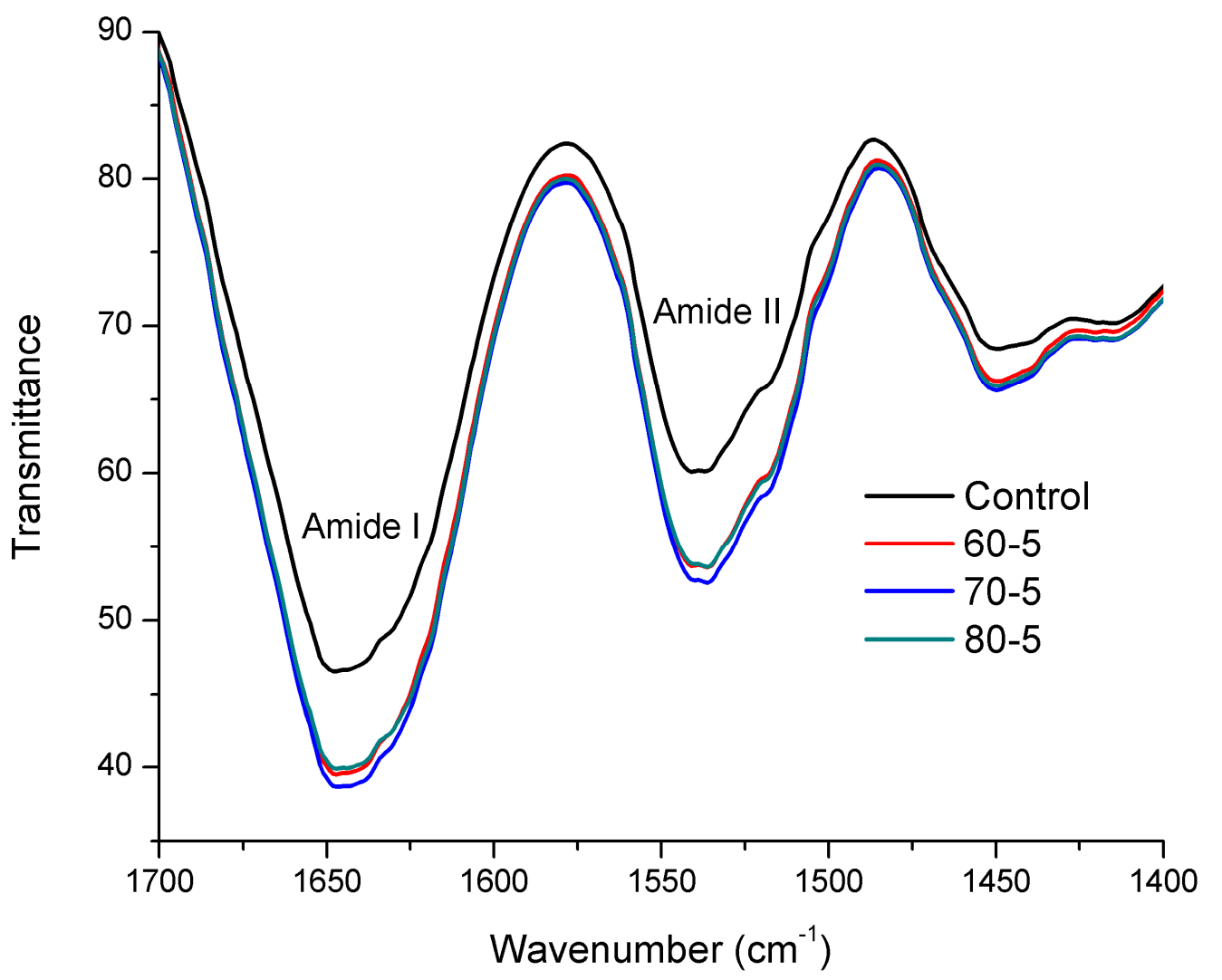

FIGURE 6: FTIR spectra of DBD plasma treated and control zein films in amide I and amide II region. A-B: Voltage (kV)-Treatment time (min).

\section{CONCLUSION}

DBD plasma treatment of zein film increases the surface roughness of the film. It also increases the equilibrium moisture content of the film. No significant difference in the thermal stability of zein was also observed for all the voltage levels and treatment times. ACP treatment led to a reorganization of the protein conformational structure as evident from the DSC and XRD results. FTIR spectrum also confirms the changes in the amide I and amide II region after plasma 
treatment. The use of different voltages and treatment times for specific food-package systems could be a promising environmentally-friendly alternative to tailor a stable in-package decontamination method using edible zein films. Further studies are suggested to understand the impact of these ACP induced changes on the packaging suitability of the zein film and ultimately on the shelf-life of food products.

\section{REFERENCES}

1. S. Isobe, Farming Japan, 37, 21-25 (2003).

2. H. Zhang and G. Mittal, Environmental Progress \& Sustainable Energy, 29, 203-220 (2010).

3. J. W. Lawton, Cereal Chemistry Journal, 79, 1-18 (2002).

4. B. B. Goldsmith, U.S. patent 922133 (1909).

5. R. Shukla and M. Cheryan, Industrial Crops and Products, 13, 171-192 (2001).

6. T. Yoshino, S. Isobe and T. Maekawa, Journal of the American Oil Chemists' Society, 77, 699-704 (2000).

7. E. A. Soliman and M. Furuta, Radiation Physics and Chemistry, 78, 651-654 (2009).

8. K. Shi, J. L. Kokini and Q. Huang, Journal of Agricultural and Food Chemistry, 57, 2186-2192 (2009).

9. A. M. Rakotonirainy, Q. Wang and G. W. Padua, J Food Sci, 66, 1108-1111 (2001).

10. J. Bai, V. Alleyne, R. D. Hagenmaier, J. P. Mattheis and E. A. Baldwin, Postharvest Biology and Technology, 28, 259-268 (2003).

11. P. J. Zapata, F. Guillén, D. Martínez-Romero, S. Castillo, D. Valero and M. Serrano, Journal of the Science of Food and Agriculture, 88, 1287-1293 (2008).

12. B. A. Niemira, Annual Review of Food Science and Technology, 3, 125-142 (2012).

13. N. Misra, B. Tiwari, K. S. M. S. Raghavarao and P. Cullen, Food Engineering Reviews, 1-12 (2011). 
14. D. Ziuzina, S. Patil, P. J. Cullen, K. M. Keener and P. Bourke, Food Microbiology In-press(2014).

15. S. K. Pankaj, N. N. Misra and P. J. Cullen, Innovative Food Science \& Emerging Technologies, 19, 153-157 (2013).

16. C. Tendero, C. Tixier, P. Tristant, J. Desmaison and P. Leprince, Spectrochimica Acta Part B: Atomic Spectroscopy, 61, 2-30 (2006).

17. C. Liu, N. Cui, N. M. D. Brown and B. J. Meenan, Surface and Coatings Technology, 185, 311-320 (2004).

18. G. Borcia, C. A. Anderson and N. M. D. Brown, Applied Surface Science, 221, 203-214 (2004).

19. F. Leroux, C. Campagne, A. Perwuelz and L. Gengembre, Journal of Colloid and Interface Science, $328,412-420$ (2008).

20. C.S. Ren, K. Wang, Q.Y. Nie, D.Z. Wang and S.H. Guo, Applied Surface Science, 255, 3421-3425 (2008).

21. W. Kun, L. Jian, R. Chunsheng, W. Dezhen and W. Younian, Plasma Science and Technology, 10, 433 (2008).

22. D. J. Upadhyay, N.-Y. Cui, C. A. Anderson and N. M. D. Brown, Applied Surface Science, 229, 352364 (2004).

23. M. Mastromatteo, G. Barbuzzi, A. Conte and M. A. Del Nobile, Innovative Food Science \& Emerging Technologies, 10, 222-227 (2009).

24. M. Pereda, M. I. Aranguren and N. E. Marcovich, Journal of Applied Polymer Science, 111, 27772784 (2009).

25. S. K. Pankaj, C. Bueno-Ferrer, N. N. Misra, L. O’Neill, A. Jiménez, P. Bourke and P. J. Cullen, Journal of Renewable Materials Surface, 2, 77-84 (2014).

26. Y. Akishev, M. Grushin, N. Dyatko, I. Kochetov, A. Napartovich, N. Trushkin, T. Minh Duc and S. Descours, Journal of Physics D: Applied Physics, 41, 235203 (2008). 
27. S. Mirabedini, H. Arabi, A. Salem and S. Asiaban, Progress in Organic Coatings, 60, 105-111 (2007).

28. M. C. Almazan-Almazan, J. I. Paredes, M. Perez-Mendoza, M. Domingo-Garcia, F. J. LopezGarzon, A. Martinez-Alonso and J. M. Tascon, J Colloid Interface Sci, 287, 57-66 (2005).

29. M. Ataeefard, S. Moradian, M. Mirabedini, M. Ebrahimi and S. Asiaban, Progress in Organic Coatings, 64, 482-488 (2009).

30. S. K. Pankaj, C. Bueno-Ferrer, N. N. Misra, L. O’Neill, A. Jiménez, P. Bourke and P. J. Cullen, Innovative Food Science \& Emerging Technologies, 21, 107-113 (2014).

31. J. W. Lawton, Cereal Chemistry Journal, 81, 1-5 (2004).

32. W. Wei and I. Baianu. Macromolecular Symposia, 1999, pp 197-209.

33. H. M. Lai, P. H. Geil and G. W. Padua, Journal of Applied Polymer Science, 71, 1267-1281 (1999).

34. Y. Wang, P. Geil and G. W. Padua, Macromolecular bioscience, 5, 1200-1208 (2005).

35. Y. Wang, A. M. Rakotonirainy and G. W. Padua, Starch - Stärke, 55, 25-29 (2003).

36. N. Singh, D. M. R. Georget, P. S. Belton and S. A. Barker, Journal of Agricultural and Food Chemistry, 57, 4334-4341 (2009).

37. C. Gao, M. Stading, N. Wellner, M. L. Parker, T. R. Noel, E. N. C. Mills and P. S. Belton, Journal of Agricultural and Food Chemistry, 54, 4611-4616 (2006).

38. K. Shi, Y. Huang, H. Yu, T.C. Lee and Q. Huang, Journal of Agricultural and Food Chemistry, 59, $56-61(2010)$. 